\title{
Electrochemical and spectroelectrochemical characterization of an iridium-based molecular catalyst for water splitting: turnover frequencies, stability, and electrolyte effects \\ Diaz Morales, O.; Hersbach, T.J.P.; Hetterscheid, D.G.H.; Reek, J.N.H.; Koper, M.T.M.
}

\section{Citation}

Diaz Morales, O., Hersbach, T. J. P., Hetterscheid, D. G. H., Reek, J. N. H., \& Koper, M. T. M. (2014). Electrochemical and spectroelectrochemical characterization of an iridium-based molecular catalyst for water splitting: turnover frequencies, stability, and electrolyte effects. Journal Of The American Chemical Society, 136(29), 10432-10439. doi:10.1021/ja504460w

Version: $\quad$ Publisher's Version

License: $\quad$ Licensed under Article 25fa Copyright Act/Law (Amendment Taverne)

Downloaded from: https://hdl.handle.net/1887/3238685

Note: To cite this publication please use the final published version (if applicable). 


\title{
Electrochemical and Spectroelectrochemical Characterization of an Iridium-Based Molecular Catalyst for Water Splitting: Turnover Frequencies, Stability, and Electrolyte Effects
}

\author{
Oscar Diaz-Morales, ${ }^{\dagger}$ Thomas J. P. Hersbach, ${ }^{\dagger}$ Dennis G. H. Hetterscheid, ${ }^{*}{ }^{\dagger}$ Joost N. H. Reek, ${ }^{\dagger}$
} and Marc T. M. Koper*, $\dagger$

${ }^{\dagger}$ Leiden Institute of Chemistry, Leiden University, P.O. Box 9502, 2300 RA, Leiden, The Netherlands

${ }^{\ddagger}$ Van’t Hoff Institute for Molecular Sciences, University of Amsterdam, Science Park 904, 1098 XH, Amsterdam, The Netherlands

Supporting Information

ABSTRACT: We present a systematic electrochemical and spectroelectrochemical study of the catalytic activity for water oxidation of an iridium- $N$-dimethylimidazolin-2-ylidene ( $\mathrm{Ir}-$ $\mathrm{NHC}-\mathrm{Me}_{2}$ ) complex adsorbed on a polycrystalline gold electrode. The work aims to understand the effect of the electrolyte properties (anions and acidity) on the activity of the
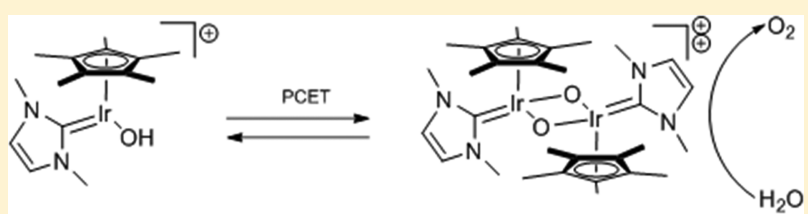
molecular catalyst and check its stability toward decomposition. Our results show that the iridium complex displays a very strong dependence on the electrolyte properties such that large enhancements in catalytic activity may be obtained by adequately choosing $\mathrm{pH}$ and anions in the electrolyte. The stability of the adsorbed compound was investigated in situ by Surface Enhanced Raman Spectroscopy and Online Electrochemical Mass Spectrometry showing that the catalyst exhibits good stability under anodic conditions, with no observable evidence for the decomposition to iridium oxide.

\section{INTRODUCTION}

Since the discovery of the ruthenium blue dimer system by Meyer, ${ }^{1}$ many molecular water oxidation catalysts have been published in literature. $^{2-4}$ Especially ruthenium based systems have been extensively studied, ${ }^{5-20}$ but also manganese, ${ }^{21-23}$ iron, ${ }^{24,25}$ cobalt, $^{26-28}$ copper, $^{29-31}$ and iridium ${ }^{32-42}$ catalysts have been addressed. The catalytic activity of these systems for water oxidation is usually studied using sacrificial stoichiometric reagents. ${ }^{43}$ Detailed (spectro-)electrochemical studies of dissolved or immobilized catalytic complexes for water oxidation are still rare. The use of sacrificial oxidants makes it difficult to properly define the thermodynamic driving force for the water oxidation reaction. An unequivocal comparison between different systems is often hampered by varying reaction conditions and the associated lack of a clearly defined oxidation potential. The importance of controlling the oxidation potential in evaluating charge transfer rates follows from the Marcus theory for electron transfer reactions, in which the thermodynamic driving force $\eta$ features prominently. ${ }^{44}$ Knowing the reaction rate or Turnover Frequency (TOF) at a well-specified overpotential is also mandatory for assessing the suitability and efficiency of the catalyst in relation to its application in a future device.

In homogeneous catalysis studies of the water oxidation reaction, Cerium Ammonium Nitrate (CAN) is frequently used as a chemical oxidant, and its corresponding oxidation potential follows from the Nernst equation:

$$
E_{\text {eq }}=E^{0}+\frac{R T}{n F} \ln \left(\frac{\left.\left[\mathrm{Ce}^{4+}\right)\right]}{\left[\mathrm{Ce}^{3+}\right]}\right)
$$

where $E^{0}$ is the standard redox potential of the couple $\mathrm{Ce}^{3+} /$ $\mathrm{Ce}^{4+}$, i.e. $1.72 \mathrm{~V}$ vs $\mathrm{SHE}^{45} \mathrm{R}$ the gas constant, $T$ temperature, $n$ $=1$ the number of electrons transferred, $F$ the Faraday constant, and $\left[\mathrm{Ce}^{4+}\right],\left[\mathrm{Ce}^{3+}\right]$ are, respectively, the activities of $\mathrm{Ce}^{4+}$ and $\mathrm{Ce}^{3+}$ in solution. Experiments are usually performed by adding solutions of cerium(IV) so that the initial concentration of cerium(III) is zero, under which conditions the oxidation potential is poorly defined (theoretically, it is infinitely high). Moreover, the oxidation potential will actually change (i.e., lower) as the reaction progresses, since $\mathrm{Ce}^{4+}$ is converted into $\mathrm{Ce}^{3+}$ so that their concentrations change in time.

An additional complication of using CAN is that, since the nitrate coordinating to cerium(IV) is partly displaced by water, the actual structure of CAN is poorly defined and very acidic conditions are employed as the $\mathrm{Ce}^{4+}$ coordinated aqua ligands readily deprotonate. ${ }^{46}$ DFT calculations have shown that the resulting cerium hydroxide is best described as a $\mathrm{Ce}$ (III) complex with a hydroxy radical coordinated. ${ }^{17}$ This can possibly lead to undesirable pathways involving transfer of hydroxyl radicals that are not relevant to water oxidation. Furthermore, Berlinguette and co-workers showed that part of the dioxygen evolved during ruthenium mediated water oxidation with CAN contains oxygen atoms that are derived from nitrate rather than from water. ${ }^{46}$ Another popular oxidant is periodate, which is stable at milder conditions compared to $\mathrm{CAN}^{43}$ however, it contains atomic oxygen that undergoes a fast exchange equilibrium with water. For that reason, $\mathrm{O}$ atom

Received: May 5, 2014

Published: June 30, 2014 
labeling studies cannot confirm whether the dioxygen produced derives from water or periodate. ${ }^{47}$ In a recent theoretical study, we showed that atomic oxygen transfer from periodate to the iridium catalyst under study is very facile, and by in situ MS spectroscopy we identified catalytic species that point to the occurrence of such nonrelevant elementary steps. ${ }^{48}$

In addition to the sometimes poorly understood identity of the chemical oxidant under reactive conditions, identification of the active catalyst can be an issue. This has almost exclusively been carried out using sacrificial reagents. On the basis of electrochemical experiments, it was claimed by the groups of De Groot and Lin that iridium complexes bearing cyclopentadienyl ligands may be stable, as no time dependence of the observed catalytic activity was observed. ${ }^{49,50}$ On the other hand, Crabtree and co-workers reported the complete deterioration of $\left[\mathrm{IrCp} *\left(\mathrm{OH}_{2}\right)_{3}\right]^{2+}\left(\mathrm{Cp}^{*}=\right.$ pentamethylcyclopentadienyl), leading to the formation of an amorphous phase of iridium oxide on the electrode. ${ }^{51-53}$ In agreement with the former studies, our group ${ }^{54}$ as well as others ${ }^{55}$ showed using DFT calculations that iridium catalysts bearing the $\mathrm{Cp}^{*}$ ligand can be active for catalytic water oxidation and those catalysts would be sufficiently stable. Crabtree and co-workers published that the $\mathrm{Cp}^{*}$ ligand is readily lost and that dinuclear molecular complexes bearing the remaining organic ligands are the true active species, using sacrificial periodate as a chemical oxidant. ${ }^{56}$ Others have shown that complete deterioration of molecular systems leading to formation of iridium oxide nanoparticles can take place, ${ }^{32,57,58}$ yet this seems to be a relative sluggish reaction $^{33}$ which is strongly dependent on the iridium concentration employed. It was also shown that these nanoparticles contain significant amounts of cerium. It is not clear to which extent these phenomena are dependent on the chemical oxidants used, and whether this chemistry can actually be translated meaningfully to the electrochemically driven dioxygen evolution reaction.

In contrast to catalytic oxidation by stoichiometric oxidants, oxidation by electrochemical techniques allows for better defined reaction conditions. The relevant oxidation potential is directly related to the applied electrode potential, leaving no doubt about the thermodynamic driving force. Provided that the electrode material used to apply the oxidizing potential is stable under the conditions of water oxidation, there are no negative or unknown side effects of chemically unstable oxidants. Furthermore, if the molecular catalyst is immobilized on the inert electrode surface, mass transport of the catalyst may be ignored and the identity and stability of the immobilized catalyst may be probed by surface sensitive spectro-electrochemical techniques. Such studies are also more meaningful in relation to real application of water oxidation catalysis in the production of solar fuels.

In this work, we perform an electrochemical and spectroelectrochemical study of the water oxidation reaction using the recently introduced $\mathrm{IrCp}^{*}-\mathrm{N}$-dimethylimidazolin-2-ylidene catalyst, immobilized on polycrystalline gold electrodes. We use voltammetry to demonstrate the significant influence of the electrolyte composition in terms of $\mathrm{pH}$ and anion identity on the TOF of the catalyst. We show in situ Surface Enhanced Raman Spectroscopy (SERS) evidence that the adsorbed catalyst dimerizes at anodic potentials and the dimer formed is the active catalytic site for the water oxidation reaction. However, the dimerization process seems to be reversible with the applied potential. SERS evidence also shows that there is no $\mathrm{IrO}_{2}$ formed. Moreover, we show by the combination of electrochemical experiments with online electrochemical mass spectroscopy (OLEMS) that the adsorbed catalyst produces only $\mathrm{O}_{2}$ under reactive conditions, and no $\mathrm{CO}_{2}$, testifying to the stability of the organic ligands.

\section{EXPERIMENTAL SECTION}

All glassware was thoroughly cleaned before starting experiments by boiling in a $1: 3$ mixture of concentrated $\mathrm{HNO}_{3}$ /concentrated $\mathrm{H}_{2} \mathrm{SO}_{4}$ to remove organic contaminations after which it was boiled five times in water. The water used for cleaning glassware and preparing solutions was demineralized and ultrafiltrated by a Milipore MiliQ system (resistivity $>18.2 \mathrm{M} \Omega \mathrm{cm}$ and TOC $<5 \mathrm{ppb}$ ). When not in use, the glassware was stored in an aqueous solution of $0.5 \mathrm{M} \mathrm{H}_{2} \mathrm{SO}_{4}$ and $1 \mathrm{~g} / \mathrm{L} \mathrm{KMnO}_{4}$. To clean the glassware from permanganate solution, it was rinsed thoroughly with water and then immersed in a 1:1 solution of concentrated $\mathrm{H}_{2} \mathrm{SO}_{4}$ and $30 \% \mathrm{H}_{2} \mathrm{O}_{2}$ to remove all particles of $\mathrm{MnO}_{2}$, after which it was rinsed with water again and boiled five times in water.

Electrolyte solutions were prepared with high quality chemicals, $\mathrm{HClO}_{4}$ (VWR, Normatom), $\mathrm{H}_{2} \mathrm{SO}_{4}$ (Merck, Ultrapur), $\mathrm{HNO}_{3}$ (Merck, Suprapur), $\mathrm{H}_{3} \mathrm{PO}_{4}$ (Merck, Suprapur), $\mathrm{NaH}_{2} \mathrm{PO}_{4}$ (Merck, Suprapur), $\mathrm{NaClO}_{4}$ (Merck, Emsure) and $\mathrm{NaOH}$ (Sigma-Aldrich, trace metals). Dissolved oxygen in solutions was removed prior to measurements by purging with argon (purity grade 5.0) for at least 30 min, and the argon was kept flowing above the solution during experiments. Experiments with ${ }^{18} \mathrm{O}$ enriched water were performed with $98 \%{ }^{18} \mathrm{O}$ water (GMP standard, from CMR), and experiments in deuterated media used $\mathrm{D}_{2} \mathrm{O}$ (Sigma-Aldrich, 99.9 atom \% D).

Electrochemical measurements were carried out in a homemade three-electrode and two-compartment cell with the reference electrode separated by a Luggin capillary. The working electrode was a homemade gold rotating disk electrode $\operatorname{RDE}(\phi=4.6 \mathrm{~mm})$, a gold wire was used as the counter electrode, and a reversible hydrogen electrode (RHE) was used as a reference; a platinum wire was connected to the reference electrode through a capacitor of $10 \mu \mathrm{F}$, acting as a low-pass filter to reduce the noise in the low current measurements. All experiments were performed at $1500 \mathrm{rpm}$, using a homemade rotator. Electrochemical measurements were performed with a potentiostat PGSTAT12 (Metrohm-Autolab). Before and between measurements, the RDE electrode was first polished with 0.3 and $0.05 \mu \mathrm{m}$ alumina paste (Buehler Limited). Subsequently the electrode was sonicated for $5 \mathrm{~min}$ to remove polishing particles.

The molecular catalyst used in this work is iridium- $N$-dimethylimidazolin-2-ylidene, which we published earlier, ${ }^{32}$ with the structure shown in Figure 1. This compound was dissolved in water to give a

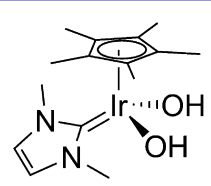

Figure 1. Structure of the iridium- $N$-dimethylimidazolin-2-ylidene complex. ${ }^{32}$

solution with a nominal concentration of $1 \times 10^{-3} \mathrm{M}$ (catalyst solution). A neutral $\mathrm{Na}$-exchanged Nafion solution was prepared by mixing one part of Nafion (5\% wt, 1000 equiv/g, Sigma-Aldrich) with one part of $0.05 \mathrm{M} \mathrm{NaOH}^{59}$ The solution to dropcast on the electrode was prepared by mixing one part of the catalyst solution with one part of Na-exchanged Nafion; $5 \mu \mathrm{L}$ of this solution was dropcasted on the gold working electrodes and dried under vacuum conditions. Currents in this work will be reported as $I_{\text {Normalized, }}$ which is the measured current divided by the amount (in $\mu \mathrm{mol}$ ) of catalyst dropcasted on the electrode, considering the nominal concentration of solution used and volume added.

In situ Surface Enhanced Raman Spectroscopy (SERS) was performed with a confocal Raman microscope (LabRam HR, Horiba Yobin Yvon) with a 50× objective. A He/Ne laser $(633 \mathrm{~nm})$ was used 
as the excitation source. Backscattered light was filtered by a $633 \mathrm{~nm}$ edge filter, directed to the spectrograph and to the detector. Details of the setup can be found in refs 60 and 61. Electrochemical SERS experiments were undertaken with an $\mu$ Autolab Type III potentiostat/ galvanostat (Metrohm-Autolab), using a homemade electrochemical cell with a small electrolyte volume necessary for the $\mathrm{H}_{2}{ }^{18} \mathrm{O}$ experiments. The electrochemical cell has one compartment and three electrodes, a gold wire as the counter electrode, $\mathrm{Ag} / \mathrm{AgCl}$ (sat. $\mathrm{KCl}$ ) as the reference electrode (potentials were recalculated and reported versus RHE), and a roughened gold surface as the working electrode. Prior to each measurement, the working electrode was mechanically polished to a mirror finish using aqueous diamond pastes (Buehler Limited) with different grain sizes to $0.25 \mu \mathrm{m}$, rinsed with MiliQ water, and sonicated during 5 min to remove all residuals of mechanical polishing. Next the gold electrode was electrochemically roughened by 25 oxidation-reduction cycles (ORC) in a $0.1 \mathrm{M}$ solution of $\mathrm{KCl}$. The ORC were performed between -0.30 and $1.20 \mathrm{~V}$ vs SCE, during which the potential was held for $30 \mathrm{~s}$ at the negative limit and for $1.3 \mathrm{~s}$ at the positive limit, a method reported to give a brownish surface that is SERS active. ${ }^{62}$ SERS measurements were carried out by dropcasting the iridium complex without $\mathrm{Na}$-exchanged Nafion, to avoid the appearance of strong signals in the spectrum, signals related to $\mathrm{R}-\mathrm{HSO}_{3}$ groups in Nafion.

Online Electrochemical Mass Spectrometry (OLEMS) experiments were performed using an EvoLution mass spectrometer system (European Spectrometry systems Ltd.). The setup has a mass detector (Prisma QMS200, Pfeiffer) which was brought to vacuum using both a turbo molecular pump (TMH-071P, Pfeiffer, flow rate $60 \mathrm{~L} \mathrm{~s}^{-1}$ ) and a rotary vane pump (Duo 2.5, Pfeiffer; flow rate $2.5 \mathrm{~m}^{3} \mathrm{~h}^{-1}$ ). During measurements, the pressure inside the mass detector chamber was around $10^{-6}$ mbar. Volatile reaction products were collected from the electrode interface by a small inlet tip positioned close $(\sim 10 \mu \mathrm{m})$ to the electrode surface using a micrometric screw system and a camera. ${ }^{63}$ The inlet tip is made with a porous Teflon cylinder (Porex) mounted in a Kel-F holder. The inlet is connected to the mass detector through a PEEK capillary. Before use, the inlet tip was cleaned for $15 \mathrm{~min}$ with a solution $0.2 \mathrm{M} \mathrm{K}_{2} \mathrm{Cr}_{2} \mathrm{O}_{7}$ in $2 \mathrm{M} \mathrm{H}_{2} \mathrm{SO}_{4}$ and rinsed thoroughly with water. The electrochemical cell used for these experiments is a twocompartment cell with three electrodes, using a gold bead electrode and a gold wire as the working and counter electrode, respectively; the reference electrode was an RHE separated from the main cell by a Luggin capillary. Before each measurement, the working electrode was electrochemically cleaned; the electrode was first oxidized in dilute sulfuric acid by applying $10 \mathrm{~V}$ for $30 \mathrm{~s}$, using a graphite bar as the counter electrode. Subsequently the gold oxide formed was removed by dipping the working electrode in a $6 \mathrm{M} \mathrm{HCl}$ solution for $30 \mathrm{~s}$.

\section{RESULTS AND DISCUSSION}

Effect of Electrolyte Anions. In a previous communication we reported ${ }^{32}$ the catalytic activity toward oxygen evolution for the $\mathrm{Ir}-\mathrm{NHC}-\mathrm{Me}_{2}$ catalyst in aqueous solution, using cerium(IV) ammonium nitrate as the chemical oxidant $\left(E_{\mathrm{Ce}(\mathrm{IV}) / \mathrm{Ce}(\mathrm{III})}^{0}=1.72 \mathrm{~V}\right.$ vs $\left.\mathrm{SHE}^{45}\right)$ and showed that under the investigated conditions the complex exhibits a a turnover frequency ${ }^{2}$ of $0.34 \mathrm{~mol} \mathrm{O}_{2} \operatorname{mol}_{\text {catalyst }}{ }^{-1} \mathrm{~s}^{-1}$, which was among the highest catalytic activities reported for an iridium based water oxidation molecular catalyst at the time. Here, we report the electrocatalytic activity of the complex immobilized on a gold surface including the effect of working conditions, such as electrolyte anions and $\mathrm{pH}$.

Figure 2 shows the current-potential profiles obtained during water oxidation catalyzed by the iridium- $N$-dimethylimidazolin-2-ylidene on gold at $\mathrm{pH} 1$ in electrolytes with different anions. The catalytic activity decreases in the order $\mathrm{HClO}_{4}>\mathrm{H}_{2} \mathrm{SO}_{4}>\mathrm{H}_{3} \mathrm{PO}_{4}>\mathrm{HNO}_{3}$. The same trend as in Figure 2 was also verified under steady-state conditions by dropcasting the Ir complex without Nafion. The $\mathrm{pH}$ in each

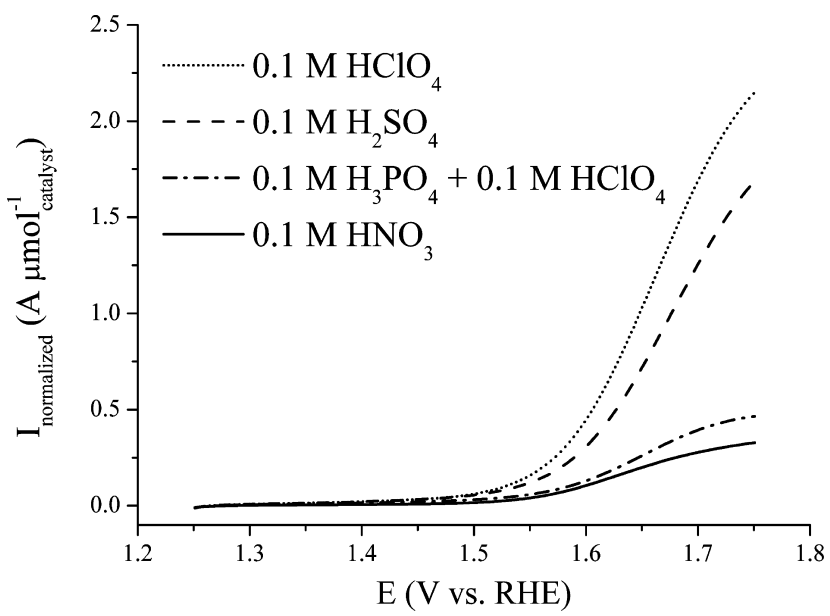

Figure 2. Current-potential profile for water oxidation catalyzed by iridium- $N$-dimethylimidazolin-2-ylidene immobilized on a gold rotating disk electrode, obtained under hydrodynamic conditions at $\mathrm{pH} 1$ in different electrolytes. $\nu=5 \mathrm{mV} \mathrm{s}^{-1}, \omega=1500 \mathrm{rpm}$.

solution was verified with a $\mathrm{pH}$ meter, and it was found that it was $1.0 \pm 0.1$, so that we can exclude any $\mathrm{pH}$ effect on the trend observed in Figure 2.

The trend observed in Figure 2 shows the importance of the electrolyte anion for the water oxidation catalysis. The varying strength of the coordination of the anions to the iridium center of the molecular complex is the most likely explanation for the trend. It has been reported that metallic iridium binds NO quite strongly, ${ }^{64}$ leading to poisoning of the electrode surface during nitrite reduction. Furthermore, the evidence reported by Ison et al. ${ }^{65}$ show that nitrate and sulfate actually coordinate to iridium species bearing $N$-heterocyclic carbenes and pentamethylcyclopentadienyl ligands. Therefore, we assume that, of the anions shown in Figure 1, the nitrate anion binds to the iridium centers the strongest, so that it blocks their access for water oxidation. This was experimentally verified in aqueous solution for the iridium catalyst studied in this work with electrospray ionization mass spectrometry (ESI-MS) in nitrate and sulfate media (see Figures $\mathrm{S} 1-\mathrm{S} 2$ in the Supporting Information). Following the same reasoning, perchlorate should coordinate the weakest and is indeed known to absorb rather weakly on electrode surfaces ${ }^{66-69}$ so it is expected that catalytic activity shows its maximum in this medium. The other anions show intermediate activities which suggest that they can bind to the iridium sites but not as strongly as nitrate does. It has been reported that iridium electrodes can reduce nitrate in sulfuric acid media, ${ }^{70}$ which suggests bisulfate should adsorb less strongly than nitrate on iridium surfaces, in agreement with the higher catalytic activity for oxygen evolution in sulfuric media. Sulfate anions adsorb more weakly than phosphate species; ${ }^{68}$ therefore, it is reasonable that bisulfate (lower charge) adsorbs more weakly than dihydrogen phosphate, explaining the higher catalytic activity in sulfuric acid media compared to phosphoric acid.

The results above show that when studying the catalytic activity of iridium-based molecular catalysts using nitrate salts of cerium(IV) as the chemical oxidant, one should be aware of the inhibitory effect of nitrate. Kinetic parameters such as turnover frequency or turnover number for water oxidation measured in that way may therefore be lower than their optimal values. 
Turnover frequencies extracted from the electrochemical experiments with the immobilized catalyst in Figure 1 are summarized in Table 1 and compared to the value reported in

Table 1. Turnover Frequency for Water Oxidation by Iridium- $\mathrm{N}$-dimethylimidazolin-2-ylidene in Solution and Immobilized on the Gold Electrode Surface

\begin{tabular}{|c|c|c|}
\hline \multirow[b]{2}{*}{ anion } & \multicolumn{2}{|c|}{ turnover frequency $\left(\mathrm{mol} \mathrm{O}_{2}[\mathrm{~mol} \text { catalyst }]^{-1} \mathrm{~s}^{-1}\right)$} \\
\hline & $\begin{array}{c}\text { catalyst in solution }^{2} \\
\mathrm{pH}=0.8\end{array}$ & $\begin{array}{c}\text { immobilized catalyst } \mathrm{pH}=1 \text {, } \\
E=1.66 \mathrm{~V} \text { vs } \mathrm{RHE}\end{array}$ \\
\hline perchlorate & - & $2.9 \pm 0.2$ \\
\hline hydrogen sulfate & - & $2.2 \pm 0.2$ \\
\hline $\begin{array}{l}\text { dihydrogen } \\
\text { phosphate }\end{array}$ & - & $1.1 \pm 0.4$ \\
\hline nitrate & 0.34 & $0.8 \pm 0.1$ \\
\hline
\end{tabular}

solution. ${ }^{32}$ The TOFs were taken at the standard equilibrium potential for the couple $\mathrm{Ce}^{4+} / \mathrm{Ce}^{3+}, 1.72 \mathrm{~V}$ vs $\mathrm{SHE}^{45}$ or $1.66 \mathrm{~V}$ vs $\mathrm{RHE}$ at $\mathrm{pH} 1$, as that was the chemical oxidant used for the homogeneous experiment. We note however that the real oxidation potential in homogeneous experiments is different, due to lack of $\mathrm{Ce}^{3+}$ at the beginning of the experiment, as explained in the Introduction. Electrochemical currents were converted into turnover frequencies using Faraday's law, i.e. TOF $=I_{\text {Normalized }} / 4 F$, assuming $100 \%$ faradaic efficiency for the reaction 1 :

$$
2 \mathrm{H}_{2} \mathrm{O} \rightarrow \mathrm{O}_{2}+4 \mathrm{H}^{+}+4 \mathrm{e}^{-}
$$

The reported turnover frequency for the molecular complex in solution ${ }^{2}$ is in reasonable agreement with the value reported in this work using the immobilized catalyst, but we emphasize that a quantitative comparison is not meaningful for the reasons mentioned in the Introduction. Also, one should consider the difference in concentration of nitrate used in each case; the results in this work were obtained in a $0.1 \mathrm{M}$ solution of nitric acid, meaning a nominal concentration of $0.1 \mathrm{M}$ in nitrate, while the kinetic data reported for the catalyst in solution ${ }^{2}$ were obtained in $0.09 \mathrm{M}$ of $\left(\mathrm{NH}_{4}\right)_{2} \mathrm{Ce}\left(\mathrm{NO}_{3}\right)_{6}$. In the latter case, the nominal concentration of nitrate in solution will depend on how labile the nitrate groups in the cerium complex are. The nitrate concentration may be almost six times higher than that used in this work, having a corresponding effect on the catalytic activity.

Turnover frequencies in Table 1 send a clear message in terms of the conditions that should be used to study the catalytic activity for oxygen evolution of molecular catalysts in solution: in selecting the chemical oxidant to drive the reaction, one should consider the effect of the anions because they may and actually will affect the kinetic data obtained. The best option is not to use chemical oxidants at all and drive the reaction electrochemically at a controlled $\mathrm{pH}$, in which case the overpotential will be properly defined during the course of the experiment.

Effect of the $\mathrm{pH}$ on the Catalytic Activity of the Molecular Complex. Figure 3 shows the current-potential profile for water oxidation in perchlorate solutions at different $\mathrm{pH}$ 's. Interestingly, there is a maximum in activity at a $\mathrm{pH}$ close to or higher than 3 , while the activity is almost negligible in alkaline $\mathrm{pH}$. Figure 3 suggests the existence of a $\mathrm{pH}$ for which the activity reaches a maximum value between $\mathrm{pH} 3$ and 11, but the intermediate $\mathrm{pH}$ was not achievable in perchlorate media due to the poor buffering capacity of this electrolyte. Additional

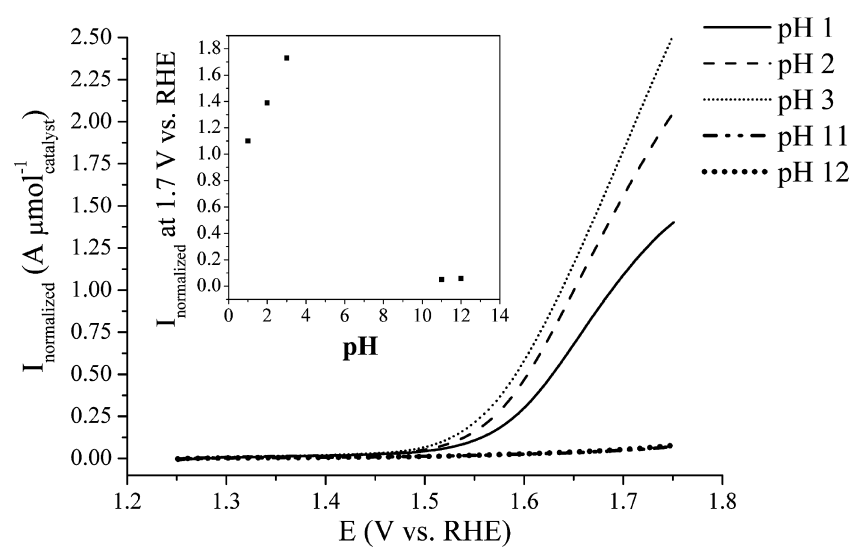

Figure 3. Current-potential profile for water oxidation catalyzed by by iridium- $\mathrm{N}$-dimethylimidazolin-2-ylidene immobilized on gold, obtained under hydrodynamic conditions at different $\mathrm{pH}$ 's in perchlorate media. $\nu=5 \mathrm{mV} \mathrm{s}^{-1}, \omega=1500 \mathrm{rpm}$. Insert: Current (activity) measured at $1.7 \mathrm{~V}$ vs RHE.

experiments were performed in phosphate buffer to study the catalytic activity at the intermediate $\mathrm{pH}$, and the results are summarized in Figure 4. By combining the $\mathrm{pH}$ dependence observed in Figures 3 and 4, we conclude that there is a maximum activity at around $\mathrm{pH} 4$, at least in phosphate media.

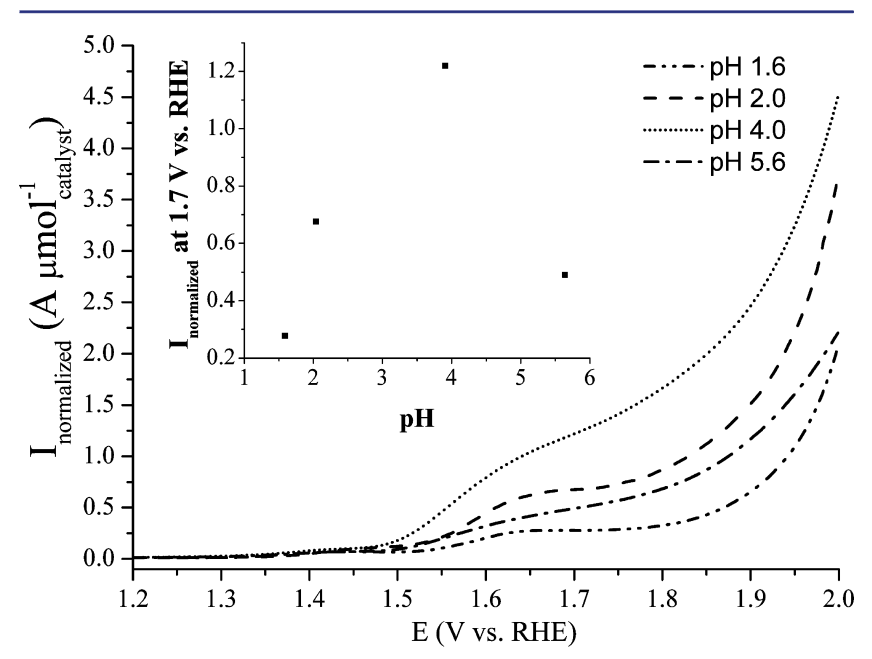

Figure 4. Current-potential profiles for water oxidation catalyzed by iridium- $\mathrm{N}$-dimethylimidazolin-2-ylidene immobilized on gold, obtained with phosphate buffer at different $\mathrm{pH} . \nu=1 \mathrm{mV} \mathrm{s}^{-1}$. Insert: Current (activity) measured at $1.7 \mathrm{~V}$ vs RHE.

Nakagawa et al. ${ }^{71}$ studied the catalytic activity of mesoporous iridium oxide as a function of $\mathrm{pH}$, in phosphate buffer; their results showed that it does not depend on $\mathrm{pH}$. Therefore, the strong $\mathrm{pH}$ dependence of the catalytic activity of the complex observed in Figures 3 and 4 supports the idea that the organometallic structure of the catalyst remains intact under the anodic working conditions, meaning that the active form of the catalyst is not iridium oxide as it has been reported in the literature $^{56,72}$ for similar molecular catalysts. Blakemore et al. ${ }^{36}$ have also observed a $\mathrm{pH}$ dependence for the water oxidation activity of their Ir complex, but they studied only neutral and alkaline media. Moreover, their experiments were carried out in a nitrate-containing electrolyte, whereas our experiments show that nitrate inhibits water oxidation, at least in acidic media, and therefore does not seem to be the most suitable medium. 
Finally, we note that for a meaningful understanding of $\mathrm{pH}$ effects, we believe that RHE is a more suitable potential reference scale than $\mathrm{NHE}$, as it takes into account the $\mathrm{pH}$ dependence of the overall reaction. On the RHE scale, reactivities are automatically compared at the same overpotential, revealing the real intrinsic $\mathrm{pH}$ dependence. As we showed recently, a $\mathrm{pH}$ dependence of the catalytic activity on the RHE scale suggests the importance of decoupled protonelectron transfer steps in the overall OER mechanism. ${ }^{73}$

The poor catalytic activity of our complex at a very alkaline $\mathrm{pH}$ might be related to a chemical conversion of the molecular complex into an inactive species. This statement is supported by ${ }^{1} \mathrm{H}$ NMR evidence (see Figures $\mathrm{S} 3-\mathrm{S} 4$ in the Supporting Information) obtained at $\mathrm{pH} 1$ and $\mathrm{pH}$ 7. The spectra show that different species are formed at alkaline $\mathrm{pH}$ compared to $\mathrm{pH}$ 1.

The above results show that the catalytic activity of a given molecular compound for water oxidation can be tuned by carefully controlling the $\mathrm{pH}$ and anions. In the specific case studied here, the activity of the iridium- $N$-dimethylimidazolin2 -ylidene complex for oxygen evolution, noted to be among the highest reported, ${ }^{32}$ can be enhanced ca. 20 times by working in perchlorate media at a $\mathrm{pH}$ close to 3 .

Stability of the Molecular Catalyst: SERS and OLEMS Experiments. In situ surface enhanced Raman spectra with the $\mathrm{Ir}-\mathrm{NHC}-\mathrm{Me}_{2}$ complex immobilized on roughened gold were acquired in $0.1 \mathrm{M} \mathrm{HClO}_{4}$ in a potential region prior to water oxidation as a function of the applied potential, as summarized in Figure 5.

The spectra in Figure 5a show two peaks located at ca. 300 and $450 \mathrm{~cm}^{-1}$ at low potential which remain visible at positive potentials albeit with lower intensity. These peaks did not show isotope shifts in deuterated or ${ }^{18} \mathrm{O}$ media (see Figure $\mathrm{S} 5$ in the Supporting Information) which suggest that the vibration modes do not involve protons or oxygen atoms. Raman spectra were also obtained for the di- $\mu$-chloro-bis[chloro(pentamethylcyclopentadienyl)iridium(III)] and the dichloro- $N$-dimethylimidazolin-2-ylidene-(penthamethylcyclopentadienyl)iridium(III) complexes in normal Raman mode (see Figure S6 in the Supporting Information). The spectra of the first compound shows two peaks at ca. 450 and $460 \mathrm{~cm}^{-1}$, which merge into one at ca. $450 \mathrm{~cm}^{-1}$ for the $N$-dimethylimidazolin-2-ylidene compound, which has only one $\mathrm{Cp}^{*}$ ligand. Other metalcyclopentadienyl complexes such as ruthenocene and osmocene are reported ${ }^{74}$ to show bending of the cyclopentadienyl ring in the region around $450 \mathrm{~cm}^{-1}$. Comparison of the normal Raman spectra of di- $\mu$-chloro-bis[chloro(pentamethylcyclopentadienyl) iridium(III)], and dichloro- $N$-dimethylimidazolin-2-ylidene-(penthamethylcyclopentanienyl)iridium(III) with the surface enhanced Raman in Figure 5 in combination with the evidence reported for the metalocenes, let us conclude that the peak at $450 \mathrm{~cm}^{-1}$ corresponds to the bending vibration of the iridium-Cp* bond. Neither the di- $\mu$ chloro-bis[chloro(pentamethylcyclopentadienyl)iridium(III)] compound nor the dichloro- $N$-dimethylimidazolin-2-ylidene(penthamethylcyclopentanienyl)iridium(III) complex showed Raman peaks at $300 \mathrm{~cm}^{-1}$, suggesting that the observed peak in Figure 4 does not correspond to vibrational modes of the absorbed complex, although we cannot make a proper assignment of the peak at $300 \mathrm{~cm}^{-1}$ based on our results.

The peak at $1030 \mathrm{~cm}^{-1}$ in Figure $5 \mathrm{a}$ has been assigned to $\mathrm{C}-$ $\mathrm{N}$ stretching modes of the imidazoline moiety, ${ }^{75}$ suggesting that the $\mathrm{N}$-dimethylimidazoline ligand remains in the active form of
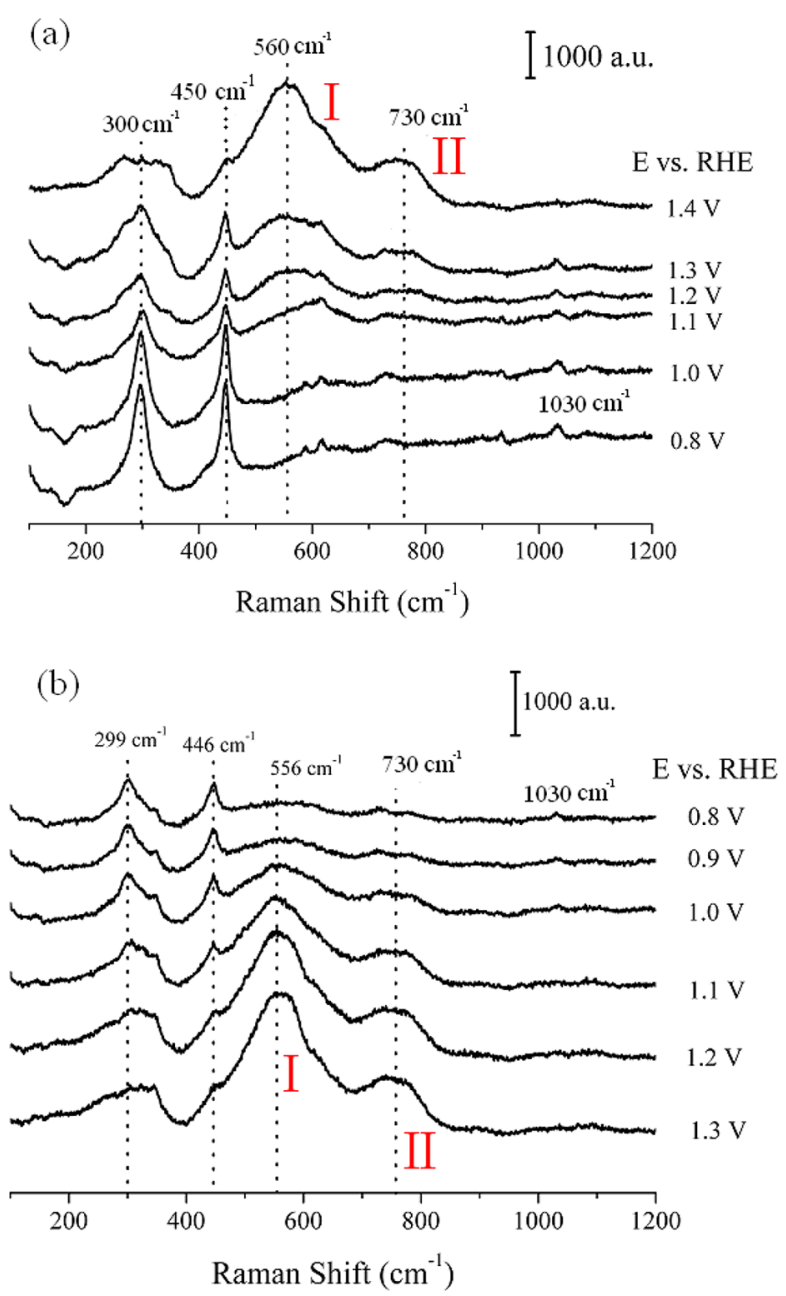

Figure 5. SERS spectra of iridium- $N$-dimethylimidazolin-2-ylidene on gold, acquired under potentiostatic conditions in $0.1 \mathrm{M} \mathrm{HClO}_{4}$ : (a) Spectra obtained by increasing the potential stepwise from 0.8 to $1.4 \mathrm{~V}$ vs RHE. (b) Spectra acquired after (a) and by decreasing the potential stepwise back to $0.8 \mathrm{~V}$ vs RHE.

the catalyst. Figure $5 \mathrm{~b}$ shows that the $\mathrm{C}-\mathrm{N}$ stretching peak remains when the potential is set back to $0.8 \mathrm{~V}$ vs RHE, showing the stability of the ligand.

Regarding the $\mathrm{Cp}^{*}$ moiety, Crabtree et al. $^{56}$ reported that, for an iridium-based molecular catalyst similar to the complex studied in this work, the Cp* acts a sacrificial placeholder that is lost in the activation process of the catalyst. The evidence in that work shows that the activation process involves the formation of a planar bis- $\mu$-oxo di-iridium(IV) compound, and the computational DFT calculations showed that this activated form of the catalyst has four Raman active vibrational modes in the regions $717-722 \mathrm{~cm}^{-1}$ and $525-532 \mathrm{~cm}^{-1}$. Those modes are expected to be sensitive to oxygen isotope labeling, showing a shift between 28 and $41 \mathrm{~cm}^{-1}$.

Peaks I and II in Figure 5a agree with the expected vibrations for the $\mu$-oxo dimer proposed by Crabtree et al., and as can be observed in Figure S5 in the Supporting Information, both peaks show sensitivity to oxygen labeling. The isotopic shifts in ${ }^{18} \mathrm{OH}_{2},{ }^{16} \mathrm{OH}_{2}$, and $\mathrm{D}_{2} \mathrm{O}$ are summarized in Table $\mathrm{S} 1$ in the Supporting Information. The shift observed in the ${ }^{18} \mathrm{O}$ labeled water also fits with that predicted for the $\mu$-oxo dimer. Furthermore, the observed lack of an isotope shift in deuterated 
media would imply that the vibrational mode does not involve any protonated species.

Figure $5 b$ shows that the peak corresponding to the $\mathrm{Ir}-\mathrm{Cp}$ * vibration (peak at ca. $450 \mathrm{~cm}^{-1}$ ) is regenerated when the potential is set back to the original values, suggesting that the dimerization process is reversible with potential and that the $\mathrm{Cp}^{*}$ is not irreversibly lost during the activation process of the complex, as stated by Crabtree et al.

SER spectra of chemically synthesized $\mathrm{IrO}_{x}$ nanoparticles ${ }^{71}$ dropcasted on a gold electrode were also measured and are shown in the Supporting Information Figure S7, corresponding well with the spectra reported in the literature. ${ }^{7677}$ These spectra are clearly different from the spectra obtained for the iridium- $\mathrm{N}$-dimethylimidazolin-2-ylidene compound, suggesting that the latter is not decomposed to iridium oxide.

The stability of the molecular complex was also confirmed by OLEMS, monitoring in situ the production of $\mathrm{O}_{2}$ and $\mathrm{CO}_{2}$ during the experiment in order to check whether the organic moieties in the complex oxidize during the catalytic oxygen evolution. Figure 6 shows the current signal and the mass signals for $\mathrm{O}_{2}(m / z 32)$ and $\mathrm{CO}_{2}(m / z 44)$.

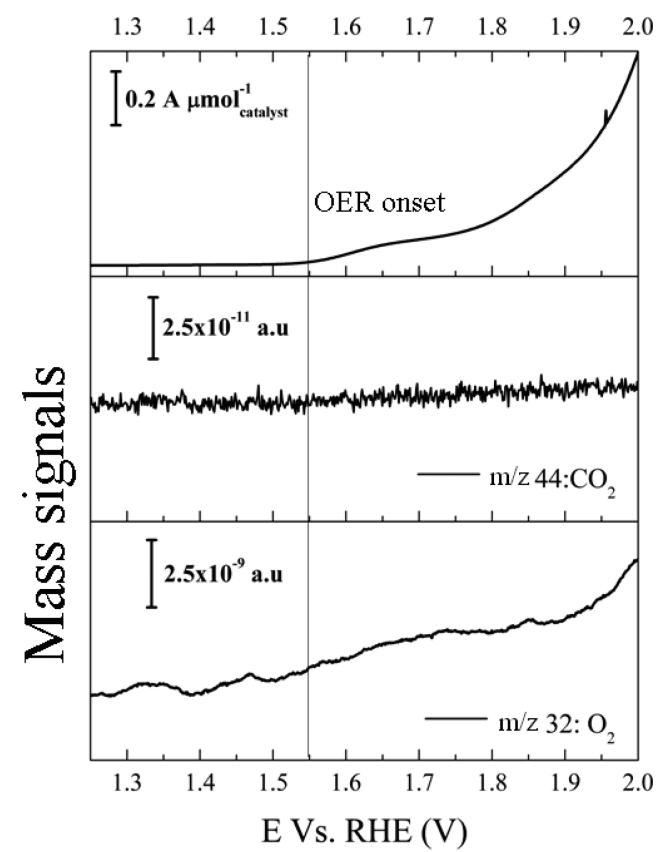

Figure 6. OLEMS signal acquired during electrochemical water oxidation in $0.1 \mathrm{M} \mathrm{HClO}_{4}$ and catalyzed by iridium- $N$-dimethylimidazolin-2-ylidene on gold. $\nu=1 \mathrm{mV} \mathrm{s}^{-1}$.

Figure 6 allows estimating the onset potential for the water oxidation on the iridium- $N$-dimethylimidazolin-2-ylidene complex as the potential at which the signal $\mathrm{m} / z 32$ starts rising: ca.1.55 V vs RHE. The most important feature that can be observed in Figure 6 is the lack of a potential dependence of the mass signal of $\mathrm{CO}_{2}$; the signal is almost flat in the potential region corresponding to water oxidation. These results show that the iridium- $N$-dimethylimidazolin-2-ylidene compound forms negligible amounts of carbon dioxide under oxidizing conditions, suggesting that the organic moieties are stable (for instance, any urea-type compound would be rapidly oxidized to $\mathrm{CO}_{2}$ under these conditions). Combined with the results obtained by SERS and $\mathrm{pH}$ dependence, we can conclude that the molecular complex studied in this work does not form iridium oxide during the catalytic reaction.

\section{CONCLUSIONS}

This paper has studied the effect of working conditions on the activity and stability of an iridium- $N$-dimethylimidazolin-2ylidene molecular catalyst adsorbed on gold by using a variety of electrochemical and spectro-electrochemical techniques. The advantage of studying immobilized molecular catalysts lies in the better defined thermodynamic driving force through the applied electrode potential, and in the ability to use spectroelectrochemical techniques to assess catalyst stability and to obtain molecular-level insight into the reaction mechanism. The turnover rate toward water oxidation of the iridium-based organometallic compound, which we define as the reaction rate per adsorbed catalyst molecule at a predefined electrode potential, is strongly dependent on the nature of the electrolyte anions, which may be ascribed to a competition between the anion and water for coordination, and on the electrolyte $\mathrm{pH}$, with an optimal $\mathrm{pH}$ close to 4 and with hardly any activity in alkaline media. By suitably tuning the $\mathrm{pH}$ and electrolyte, the TOF for water oxidation can be enhanced by a factor of 20. In situ SERS experiments showed that the active state of the molecular catalyst may involve a bis- $\mu$-oxo iridium dimer that is reversibly formed when the potential is scanned to positive values. The SERS and online electrochemical mass spectrometry experiments together with the $\mathrm{pH}$ dependence show that the iridium-based molecular complex does not decompose into iridium oxide during the oxygen evolution reaction. As a final more general conclusion, it is essential to clearly define the electrolyte $\mathrm{pH}$, electrolyte anion (or electrolyte composition in general), and thermodynamic driving force (electrode potential) in any meaningful comparison of turnover frequencies between different molecular water splitting catalysts.

\section{ASSOCIATED CONTENT}

\section{S Supporting Information}

ESI-MS spectra of $\operatorname{Ir}(\mathrm{OH})_{2}$ and iridium- $N$-dimethylimidazolin2-ylidene from different electrolytes and $\mathrm{pH}$; transmission Raman spectra of di- $\mu$-chloro-bis[chloro(pentamethylcyclopentadienyl) iridium(III) and dichloro- $N$-dimethylimidazolin2-ylidene-penthamethylcyclopentanienyl) iridium(III); SER spectra of Ir-oxide nanoparticles on gold; table of main Raman frequencies from Figure 5 in isotopically labeled water. This material is available free of charge via the Internet at http://pubs.acs.org.

\section{AUTHOR INFORMATION}

\section{Corresponding Authors}

d.g.h.hetterscheid@chem.leidenuniv.nl m.koper@chem.leidenuniv.nl

\section{Notes}

The authors declare no competing financial interest.

\section{ACKNOWLEDGMENTS}

This research is financed in part by the BioSolar Cells open innovation consortium, supported by the Dutch Ministry of Economic Affairs, Agriculture and Innovation. 


\section{REFERENCES}

(1) Gersten, S. W.; Samuels, G. J.; Meyer, T. J. J. Am. Chem. Soc. 1982, 104, 4029.

(2) Hetterscheid, D. G. H.; Reek, J. N. H. Angew. Chem., Int. Ed. 2012, 51, 9740.

(3) Wasylenko, D. J.; Palmer, R. D.; Berlinguette, C. P. Chem. Commun. 2013, 49, 218.

(4) Sala, X.; Romero, I.; Rodriguez, M.; Escriche, L.; Llobet, A. Angew. Chem., Int. Ed. 2009, 48, 2842.

(5) Wasylenko, D. J.; Ganesamoorthy, C.; Koivisto, B. D.; Henderson, M. A.; Berlinguette, C. P. Inorg. Chem. 2010, 49, 2202.

(6) Wasylenko, D. J.; Ganesamoorthy, C.; Henderson, M. A.; Koivisto, B. D.; Osthoff, H. D.; Berlinguette, C. P. J. Am. Chem. Soc. 2010, 132, 16094.

(7) Concepcion, J. J.; Tsai, M. K.; Muckerman, J. T.; Meyer, T. J. J. Am. Chem. Soc. 2010, 132, 1545.

(8) Concepcion, J. J.; Jurss, J. W.; Norris, M. R.; Chen, Z. F.; Templeton, J. L.; Meyer, T. J. Inorg. Chem. 2010, 49, 1277.

(9) Concepcion, J. J.; Jurss, J. W.; Brennaman, M. K.; Hoertz, P. G.; Patrocinio, A. O. T.; Iha, N. Y. M.; Templeton, J. L.; Meyer, T. J. Acc. Chem. Res. 2009, 42, 1954.

(10) Duan, L. L.; Araujo, C. M.; Ahlquist, M. S. G.; Sun, L. C. Proc. Natl. Acad. Sci. U.S.A. 2012, 109, 15584.

(11) Duan, L. L.; Bozoglian, F.; Mandal, S.; Stewart, B.; Privalov, T.; Llobet, A.; Sun, L. C. Nat. Chem. 2012, 4, 418.

(12) Nyhlen, J.; Duan, L. L.; Akermark, B.; Sun, L. C.; Privalov, T. Angew. Chem., Int. Ed. 2010, 49, 1773.

(13) Duan, L. L.; Fischer, A.; Xu, Y. H.; Sun, L. C. J. Am. Chem. Soc. 2009, 131, 10397.

(14) Kaveevivitchai, N.; Chitta, R.; Zong, R. F.; El Ojaimi, M.; Thummel, R. P. J. Am. Chem. Soc. 2012, 134, 10721.

(15) Boyer, J. L.; Polyansky, D. E.; Szalda, D. J.; Zong, R. F.; Thummel, R. P.; Fujita, E. Angew. Chem., Int. Ed. 2011, 50, 12600.

(16) Yamazaki, H.; Hakamata, T.; Komi, M.; Yagi, M. J. Am. Chem. Soc. 2011, 133, 8846

(17) Yoshida, M.; Masaoka, S.; Abe, J.; Sakai, K. Chem-Asian J. 2010, 5, 2369.

(18) Lopez, I.; Ertem, M. Z.; Maji, S.; Benet-Buchholz, J.; Keidel, A.; Kuhlmann, U.; Hildebrandt, P.; Cramer, C. J.; Batista, V. S.; Llobet, A. Angew. Chem., Int. Ed. 2014, 53, 205.

(19) Maji, S.; Vigara, L.; Cottone, F.; Bozoglian, F.; Benet-Buchholz, J.; Llobet, A. Angew. Chem., Int. Ed. 2012, 51, 5967.

(20) Mola, J.; Dinoi, C.; Sala, X.; Rodriguez, M.; Romero, I.; Parella, T.; Fontrodona, X.; Llobet, A. Dalton Trans. 2011, 40, 3640.

(21) Karlsson, E. A.; Lee, B. L.; Akermark, T.; Johnston, E. V.; Karkas, M. D.; Sun, J. L.; Hansson, O.; Backvall, J. E.; Akermark, B. Angew. Chem., Int. Ed. 2011, 50, 11715.

(22) Limburg, J.; Vrettos, J. S.; Liable-Sands, L. M.; Rheingold, A. L.; Crabtree, R. H.; Brudvig, G. W. Science 1999, 283, 1524.

(23) Limburg, J.; Vrettos, J. S.; Chen, H. Y.; de Paula, J. C.; Crabtree, R. H.; Brudvig, G. W. J. Am. Chem. Soc. 2001, 123, 423.

(24) Fillol, J. L.; Codola, Z.; Garcia-Bosch, I.; Gomez, L.; Pla, J. J.; Costas, M. Nat. Chem. 2011, 3, 807.

(25) Ellis, W. C.; McDaniel, N. D.; Bernhard, S.; Collins, T. J. J. Am. Chem. Soc. 2010, 132, 10990.

(26) Wasylenko, D. J.; Ganesamoorthy, C.; Borau-Garcia, J.; Berlinguette, C. P. Chem. Commun. 2011, 47, 4249.

(27) Yin, Q. S.; Tan, J. M.; Besson, C.; Geletii, Y. V.; Musaev, D. G.; Kuznetsov, A. E.; Luo, Z.; Hardcastle, K. I.; Hill, C. L. Science 2010, $328,342$.

(28) Dogutan, D. K.; McGuire, R.; Nocera, D. G. J. Am. Chem. Soc. 2011, 133, 9178.

(29) Barnett, S. M.; Goldberg, K. I.; Mayer, J. M. Nat. Chem. 2012, 4, 498.

(30) Zhang, M. T.; Chen, Z. F.; Kang, P.; Meyer, T. J. J. Am. Chem. Soc. 2013, 135, 2048.

(31) Chen, Z. F.; Meyer, T. J. Angew. Chem., Int. Ed. 2013, 52, 700.

(32) Hetterscheid, D. G. H.; Reek, J. N. H. Chem. Commun. 2011, 47, 2712
(33) Hintermair, U.; Hashmi, S. M.; Elimelech, M.; Crabtree, R. H. J. Am. Chem. Soc. 2012, 134, 9785.

(34) Brewster, T. P.; Blakemore, J. D.; Schley, N. D.; Incarvito, C. D.; Hazari, N.; Brudvig, G. W.; Crabtree, R. H. Organometallics 2011, 30, 965.

(35) Parent, A. R.; Blakemore, J. D.; Brudvig, G. W.; Crabtree, R. H. Chem. Commun. 2011, 47, 11745.

(36) Blakemore, J. D.; Schley, N. D.; Balcells, D.; Hull, J. F.; Olack, G. W.; Incarvito, C. D.; Eisenstein, O.; Brudvig, G. W.; Crabtree, R. H. J. Am. Chem. Soc. 2010, 132, 16017.

(37) Petronilho, A.; Rahman, M.; Woods, J. A.; Al-Sayyed, H.; Muller-Bunz, H.; MacElroy, J. M. D.; Bernhard, S.; Albrecht, M. Dalton Trans. 2012, 41, 13074.

(38) Lalrempuia, R.; McDaniel, N. D.; Muller-Bunz, H.; Bernhard, S.; Albrecht, M. Angew. Chem., Int. Ed. 2010, 49, 9765.

(39) McDaniel, N. D.; Coughlin, F. J.; Tinker, L. L.; Bernhard, S. J. Am. Chem. Soc. 2008, 130, 210.

(40) Bucci, A.; Savini, A.; Rocchigiani, L.; Zuccaccia, C.; Rizzato, S.; Albinati, A.; Llobet, A.; Macchioni, A. Organometallics 2012, 31, 8071.

(41) Savini, A.; Bellachioma, G.; Bolano, S.; Rocchigiani, L.; Zuccaccia, C.; Zuccaccia, D.; Macchioni, A. ChemSusChem 2012, 5, 1415.

(42) Savini, A.; Bellachioma, G.; Ciancaleoni, G.; Zuccaccia, C.; Zuccaccia, D.; Macchioni, A. Chem. Commun. 2010, 46, 9218.

(43) Parent, A. R.; Crabtree, R. H.; Brudvig, G. W. Chem. Soc. Rev. 2013, 42, 2247.

(44) Marcus, R. A. Angew. Chem., Int. Ed. Engl. 1993, 32, 1111.

(45) West, R. Handbook of Chemistry and Physics, 53rd ed.; CRC Press: Cleveland, 1972.

(46) Wasylenko, D. J.; Ganesamoorthy, C.; Henderson, M. A.; Berlinguette, C. P. Inorg. Chem. 2011, 50, 3662.

(47) Pecht, I.; Luz, Z. J. Am. Chem. Soc. 1965, 87, 4068

(48) Hetterscheid, D. G. H.; Reek, J. N. H. Eur. J. Inorg. Chem. 2014, $2014,742$.

(49) Joya, K. S.; Subbaiyan, N. K.; D’Souza, F.; de Groot, H. J. M. Angew. Chem., Int. Ed. 2012, 51, 9601.

(50) deKrafft, K. E.; Wang, C.; Xie, Z. G.; Su, X.; Hinds, B. J.; Lin, W. B. ACS Appl. Mater. Interfaces 2012, 4, 608.

(51) Huang, J.; Blakemore, J. D.; Fazi, D.; Kokhan, O.; Schley, N. D.; Crabtree, R. H.; Brudvig, G. W.; Tiede, D. M. Phys. Chem. Chem. Phys. 2014, 16, 1814.

(52) Blakemore, J. D.; Mara, M. W.; Kushner-Lenhoff, M. N.; Schley, N. D.; Konezny, S. J.; Rivalta, I.; Negre, C. F. A.; Snoeberger, R. C.; Kokhan, O.; Huang, J.; Stickrath, A.; Tran, L. A.; Parr, M. L.; Chen, L. X.; Tiede, D. M.; Batista, V. S.; Crabtree, R. H.; Brudvig, G. W. Inorg. Chem. 2013, 52, 1860.

(53) Blakemore, J. D.; Schley, N. D.; Olack, G. W.; Incarvito, C. D.; Brudvig, G. W.; Crabtree, R. H. Chem. Sci. 2011, 2, 94.

(54) Venturini, A.; Barbieri, A.; Reek, J. N. H.; Hetterscheid, D. G. H. Chem.-Eur. J. 2014, chem.201303796.

(55) Zhou, M.; Balcells, D.; Parent, A. R.; Crabtree, R. H.; Eisenstein, O. ACS Catal. 2012, 2, 208.

(56) Hintermair, U.; Sheehan, S. W.; Parent, A. R.; Ess, D. H.; Richens, D. T.; Vaccaro, P. H.; Brudvig, G. W.; Crabtree, R. H. J. Am. Chem. Soc. 2013, 135, 10837.

(57) Hong, D. C.; Murakami, M.; Yamada, Y.; Fukuzumi, S. Energ Environ. Sci. 2012, 5, 5708.

(58) Grotjahn, D. B.; Brown, D. B.; Martin, J. K.; Marelius, D. C.; Abadjian, M. C.; Tran, H. N.; Kalyuzhny, G.; Vecchio, K. S.; Specht, Z. G.; Cortes-Llamas, S. A.; Miranda-Soto, V.; van Niekerk, C.; Moore, C. E.; Rheingold, A. L. J. Am. Chem. Soc. 2011, 133, 19024.

(59) Suntivich, J.; Gasteiger, H. A.; Yabuuchi, N.; Shao-Horn, Y. J. Electrochem. Soc. 2010, 157, B1263.

(60) Diaz-Morales, O.; Calle-Vallejo, F.; de Munck, C.; Koper, M. T. M. Chem. Sci. 2013, 4, 2334.

(61) Lai, S. C. S.; Kleyn, S. E. F.; Rosca, V.; Koper, M. T. M. J. Phys. Chem. C 2008, 112, 19080.

(62) Gao, P.; Gosztola, D.; Leung, L. W. H.; Weaver, M. J. J. Electroanal. Chem. 1987, 233, 211. 
(63) Wonders, A. H.; Housmans, T. H. M.; Rosca, V.; Koper, M. T. M. J. Appl. Electrochem. 2006, 36, 1215.

(64) Duca, M.; van der Klugt, B.; Koper, M. T. M. Electrochim. Acta 2012, 68, 32.

(65) Feng, Y.; Jiang, B.; Boyle, P. A.; Ison, E. A. Organometallics 2010, 29, 2857.

(66) Borkowska, Z.; Slimming, U. Journal of Electroanalytical Chemistry and Interfacial Electrochemistry 1991, 312, 237.

(67) Clavilier, J.; Van Huong, C. N. Journal of Electroanalytical Chemistry and Interfacial Electrochemistry 1977, 80, 101.

(68) Silva, F.; Martins, A. J. Electroanal. Chem. 1999, 467, 335.

(69) Angerstein-Kozlowska, H.; Conway, B. E.; Hamelin, A.; Stoicoviciu, L. Electrochim. Acta 1986, 31, 1051.

(70) Dima, G. E.; de Vooys, A. C. A.; Koper, M. T. M. J. Electroanal. Chem. 2003, 554-555, 15.

(71) Nakagawa, T.; Beasley, C. A.; Murray, R. W. J. Phys. Chem. C 2009, 113, 12958

(72) Limburg, B.; Bouwman, E.; Bonnet, S. Coord. Chem. Rev. 2012, 256, 1451.

(73) Koper, M. T. M. Chem. Sci. 2013, 4, 2710.

(74) Lokshin, B. V.; Aleksanian, V. T.; Rusach, E. B. J. Organomet. Chem. 1975, 86, 253.

(75) Majoube, M.; Henry, M.; Chinsky, L.; Turpin, P. Y. Chem. Phys. 1993, 169, 231.

(76) Musić, S.; Popović, S.; Maljković, M.; Skoko, Z.; Furić, K.; Gajović, A. Mater. Lett. 2003, 57, 4509.

(77) Thanawala, S.; Georgiev, D. G.; Baird, R. J.; Auner, G. Thin Solid Films 2007, 515, 7059. 